\title{
UM MUIRAQUITÃ EM SEU CONTEXTO ARQUEOLÓGICO NO LENDÁRIO AMAZÔNICO
}

\author{
Marcondes Lima da Costa iD $\triangle$ \\ Universidade Federal do Pará - PPGG/IG. \\ Renato Kipnis (D) $\triangle$ \\ Scientia Consultoria Científica \\ Glayce Jholy Souza da Silva iD $\triangle$ \\ Universidade Federal do Pará - PPGG/IG
}

Tallyta Suenny Araújo Silva (D) $\triangle$

Suyanne Flávia Santos Rodrigues (iD $\triangle$

Denise Pahl Schaan (In memoriam) 
Em salvamento arqueológico realizado pelo PPGA/UFPA em 2011, no porto da cidade de Santarém (Pará), foi encontrado um pingente lítico com as características morfológicas de um muiraquitã, aqui denominado de muiraquitã Santarém. Ele foi um dos primeiros muiraquitãs encontrados em ambiente contextualizado no vale amazônico. Enquanto se tem em mente que esses pingentes sejam elaborados em jade nefrítico, o Santarém, embora lítico e de cor cinza-esverdeado, foi entalhado em clorita-sericita-quartzo xisto, uma rocha metamórfica de baixo grau recorrente. Mesmo assim, o achado é raro, em função do design e uso, além de representar objetos pré-históricos socioculturais, que no design encontram paralelos na pré-história ao longo da costa atlântica amazônica e nas ilhas do Caribe. Apesar da raridade dos muiraquitãs, a caracterização químico-mineralógica realizada em coleções arqueologicamente descontextualizadas, e agora em peças exumadas in situ por meio de escavações controladas, tem demonstrado que a matéria-prima empregada na confecção desses adornos foi, na maioria, o jade nefrítico (tremolita- actinolita), que pode ser encontrada no baixo Amazonas, o que desmitifica a ideia de matéria-prima exótica. Por outro lado, no muiraquitã Santarém (ST-42/602), a clorita-sericita-quartzo xisto, comum, sugere que algumas peças se diferenciavam pelo tipo de matéria-prima, pensadas, talvez para uso próprio, como da cultura tapajônica, enquanto outras mais raras, eram utilizadas nas redes de trocas entre as elites amazônicas.

Palavras-chave: Nefrita; Jade; Clorita; Sericita; Mar do Caribe.

\section{A MUIRAQUITAN IN ITS ARCHAEOLOGICAL CONTEXT IN THE LEGENDARY AMAZON}

\section{ABSTRACT}

In an archaeological rescue carried out by the Graduate

Program in Anthropology at UFPA in 2011, in the port of the city of Santarém (State of Pará, Brazil), a lithic pendant with the morphological characteristics of a muiraquitã (called here muiraquitã Santarém) was found, being therefore one of the first in the contextualized environment of the Amazon valley. While keeping in mind that these pendants are made of nephritic jade, Santarém, although lithic and greenish gray in color, was carved in chloritesericite-quartz schist, a recurrent low grade metamorphic rock. Even so, the finding is rare, due to its design and prehistoric use, in addition to representing socio-cultural objects, which in design find prehistoric parallels along the Atlantic coastal region and in the Caribbean islands. Keywords: Nephite; Jade; Chlorite; Sericite; Caribbean Sea.

\section{UN MUIRAQUITANO EN SU CONTEXTO ARQUEOLÓGICO EN LA LEGENDARIO AMAZÓNICO}

En un rescate arqueológico realizado por el Programa de Posgrado en Antropología de la UFPA en 2011 en el puerto de la ciudad de Santarém (Pará), se encontró un colgante lítico con las características morfológicas de un muiraquitã, aquí llamado muiraquitã Santarém, por lo tanto, uno de los primeros en el ambiente. contextualizado en el valle amazónico. Si bien se tiene en cuenta que estos colgantes están hechos de jade nefrítico, Santarém, aunque lítico y de color gris verdoso, fue tallado en esquisto de clorita-sericita-cuarzo, una roca metamórfica recurrente de bajo grado. Aun así, el hallazgo es raro, por el diseño y uso, además de representar objetos socioculturales prehistóricos, que en diseño encuentran paralelos en la prehistoria a lo largo de la costa atlántica atlántica y en las islas del Caribe.

Palavras-chave: Nefrita; Jade; Clorita; Sericita; Mar del Caribe 


\section{INTRODUÇÃO}

Em 2011, a profa. Dra. Denise Pahl Schaan (PPGA/UFPA), em Belém do Pará, nos honrou com a guarda de um pingente em forma batraquiana, encontrado durante salvamento arqueológico no porto de Santarém, que correspondia classicamente a um muiraquitã. Na verdade, ela desejava que fizéssemos uma investigação químicomineralógica visando à caracterização geológica da matéria-prima empregada na confecção desta linda obra de arte cultural e, a partir destes dados, consubstanciar os seus estudos arqueológicos na Amazônia. Infelizmente, diante dos inúmeros afazeres e múltiplos objetivos dela, em ambiente rico de problemas vastos no cenário arqueológico da Amazônia, que lhe demandava assumir muitos compromissos, não nos foi possível apresentar de forma conjunta os dados que obtivemos sobre o referido achado. E o destino quis, por bem, retirar de nosso convívio muito prematuramente, em 2018, a professora Denise Pahl Schaan. Este trabalho é dedicado cem por cento a ela, não só pela lembrança, mas principalmente pelo fato de ter sido fruto de seu árduo e dedicado trabalho e de sua grande equipe de colaboradores.

O pingente tipo muiraquitã, cujo tombamento ST-42/602, foi encontrado durante escavação arqueológica sistemática no sítio Porto de Santarém, como parte do Programa de Salvamento
Arqueológico do Sitio PA-ST-42: Porto de Santarém, ano 2. Esse programa foi conduzido pela UFPA em cumprimento ao Convênio n. 02/2010, celebrado entre a universidade e a Companhia Docas do Pará (CDP), em 30 de março de 2011, se estendendo até 30 de junho de 2012. A pesquisa foi autorizada pela Portaria n. 21, de 28/06/2011, publicada no DOU n.123, de 29/06/2011 (Schaan 2012a).

Por causa da ausência de muiraquitãs exumados in situ de sítios arqueológicos, pouco se conhece sobre os processos e locais de sua produção, assim como sobre dispersão e circulação desses adornos únicos na Arqueologia amazônica. O estudo físico, mineralógico e químico do muiraquitã ST-42/602 tem o objetivo de criar uma referência no sentido de contribuir para o entendimento desses artefatos nos processos histórico-culturais e evolutivos da ocupação humana na região amazônica.

\section{Muiraquitãs}

Apesar de relatos etno-históricos, desde o século XVIII, sobre a existência de muiraquitãs entre os povos que habitavam a região do Tapajós, é no final do século XIX que as primeiras hipóteses sobre origem e dispersão desses adornos são construídas. As estatuetas foram consideradas como artefatos provenientes de outras regiões, seja da Amazônia colombiana, da região caribenha ou até mesmo da Ásia (Fonseca 2010; Navarro \& Prous 2020). 
As muiraquitãs são artefatos raros, e apresentam furos laterais que sugerem seu uso normalmente confeccionados em "pedra verde", como pingente ou adorno (Silva et al. 1998, Costa até muito recentemente na região amazônica, et al. 2002b, Meirelles e Costa 2012, Navarro et al. nunca tinham sido coletados em contexto 2017, Navarro e Prous 2020). Ainda é incerto se arqueológico controlado e bem-documentado. São figuras em sua maioria em formato de batráquio, representando corpos humanos e animais e, mais recentemente, têm sido interpretados como artefatos cerimoniais de prestígio entre as elites amazônicas, cuja circulação se deu através de uma rede de trocas a longa distância em uma área que abrangia toda a porção Norte da América do Sul e, provavelmente, a América Central, com diversos centros de produção e dispersão (Aires da Fonseca 2010, Barreto 2017, Boomert 1987, Rostain 2013, Navarro \& Prous 2020).

$\mathrm{Na}$ Amazônia brasileira, o muiraquitã é citado como ocorrendo mais frequentemente na região de domínio dos rios Nhamundá-Trombetas, Tapajós, Amazonas e na Ilha de Marajó (Barata 1954, Boomert 1987, Fonseca 2010, Lima 2018, Moraes et al. 2013), além das estearias na Baixada Maranhense (Lopes 1924, Navarro 2013, Navarro et al. 2017), sendo encontrado também um exemplar na região do Xingu.

Muiraquitãs são artefatos líticos polidos, confeccionados em minerais ou rochas esverdeadas (geralmente jadeítas, tremolitaactinolita, serpentinitas, nefritas, amazonitas etc.) os muiraquitãs eram confeccionados em alguns poucos centros de produção ou se eram produzidos em vários locais diferentes (Neves 2006).

Segundo Boomert (1987), Meirelles e Costa (2012) e Rostain (2013), os muiraquitãs começaram a serem produzidos por volta de 400 a.C. e continuaram sendo confeccionados até a chegada dos colonizadores europeus. Vale ressaltar que quatro zonas de produção de "pedra verde" são conhecidas: (i) $\mathrm{O}$ baixo Amazonas, associado às tradições Incisa-Ponteada e Policroma do Marajó; (ii) A costa central do Suriname, associada à cultura Araquinoide; (iii) O entorno do lago Valencia, na costa da Venezuela; (iv) O Norte das Antilhas menores, associada à cultura Saladoide.

A peça ST-42/602 foi o primeiro artefato, em sua concepção clássica, considerado como pingente batraquiano encontrado em contexto arqueológico amazônico clássico. O Amazonas de Orellana e Carvajal, de forma indubitável, é apresentado brevemente em Schaan e Alves (2015), além de divulgado pelo relatório de Schaan (2012a).

Na Baixada Maranhense, Lopes (1924) reporta que vários pingentes equivalentes a 
muiraquitãs ${ }^{1}$ teriam sido encontrados no lago Cajari, isso, claro, ainda no século passado. $\mathrm{Na}$ região, em escavações recentes realizadas no sítio Boca do Rio, um sítio tipo estearia na Baixada Maranhense, foi encontrado um muiraquitã que atende à definição de Barata (1954), além de estar contextualizado. $\mathrm{O}$ achado resultou de pesquisa sistemática com escavações de quadrículas de $1 \mathrm{x}$ $1 \mathrm{~m}$, que apresentaram grande riqueza em material cerâmico, lítico e matéria orgânica (Navarro et al. 2017).

$\mathrm{O}$ interesse pelas pedras verdes usadas como amuletos e denominadas também de muiraquitãs é antigo. Charles Marie de la Condamine, em 1743, quando de sua longa e demorada viagem descendo o rio Amazonas desde Quito, relatou a ocorrência desses amuletos na região do baixo Amazonas, principalmente entre os índios Tapajó (Navarro et al. 2017), portanto, na região da atual influência de Santarém. Rodrigues (1899) foi um dos primeiros trabalhos a ressaltar a importância da região, mais tarde polarizada por Santarém, para esses artefatos e tentar explicar a sua origem, considerando-a de procedência asiática, tendo em vista que as pedras verdes seriam de jade, pedra não conhecida na região, e sim dominante na Ásia oriental. Parece inquestionável a importância da atual região centralizada em Santarém (baixo Amazonas) como um dos polos de produção e/ou circulação e entreposto pré-histórico de pingentes como o muiraquitã. Por outro lado, Moraes et al. (2013), na mesma linha de Barata (1954), defendem a cadeia produtiva local para os muiraquitãs, com base em análise de material lítico coletado também em área do porto de Santarém. Ela inclusive coincide com a história "lendária" das guerreiras amazonas contada por Frei Gaspar de Carvajal por ocasião das aventuras de descida do rio Amazonas ainda em 1541-1542, sob o comando de Francisco de Orellana.

Embora a expressão muiraquitã fosse conhecida, a forma do objeto não era claramente definida, foi Barata (1954) quem defendeu que os muiraquitãs eram artefatos de pedra verde, com forma batraquiana e furos laterais. Para ele, o termo é etimologicamente de origem tupi, que significaria uma conta em forma de sapo ou rã, utilizado como pingente ou adorno, indicado pela presença de furos laterais. Apreciados e valorizados por museus e colecionadores, esses pingentes, no entanto, só foram investigados quanto a sua composição química e mineralógica a partir dos anos 2000, tendo como material de partida os exemplares depositados em alguns museus (MAE, Museu Paraense Emílio 
Goeldi, Museu do Encontro do Estado do Pará, (Boomert 1987, Queffelec et al. 2018, Falci et al. e os de alguns colecionadores particulares), 2020, Costa et al. 2020).

nenhum deles, no entanto, contextualizado. Os resultados obtidos foram muito importantes para, em parte, desmistificar a sua constituição em jade, um argumento para a procedência asiática. Ficou claro que foram esculpidos em diversos materiais, predominando aqueles em tremolita e tremolitaactinolita, que constituem as pedras verdes, e se equivalem ao jade nefrítico, além daqueles em talco, clorita, amazonita, variscita, quartzo prásio, que tendem a serem verdes, além de albita, anortita e pirofilita (Meirelles \& Costa 2012). Na coleção do Museu do Encontro, em Belém, foram encontrados quatro exemplares a jadeíta, desprovidos de qualquer informação arqueológica (Silva et al. 1998, Costa et al. 2002a \&2002b, Meirelles \& Costa 2012). A mais recente descoberta feita em ambiente contextualizado é aquele de Boca do Rio na Baixada Maranhense, citado anteriormente, esculpido em tremolita e tremolita-actinolita (Navarro et al. 2017).

Os muiraquitãs foram e ainda continuam sendo encontrados em terrenos do baixo Amazonas até o Maranhão. Artefatos similares, com designs equivalentes aos do amazônico, embora não conhecidos pelo termo muiraquitã e confeccionados em diversos materiais, incluindo jade nefrítico, têm sido reportados em várias regiões do Caribe, nas pequenas e grandes Antilhas e na Venezuela
O presente artigo descreve os aspectos morfológicos gerais, mineralógicos e químicos de um muiraquitã encontrado em contexto arqueológico em Santarém no estado do Pará, visando situá-lo no contexto das demais peças tidas como muiraquitãs na Amazônia (Schaan 2012a).

\section{MATERIAIS E MÉTODOS}

Salvamento arqueológico e a descoberta do muiraquitã

O muiraquitã de tombamento ST-42/602, doravante denominado de muiraquitã ou pingente Santarém, foi encontrado durante os trabalhos sistemáticos de salvamento arqueológico dentro do Programa de Salvamento Arqueológico do Sitio PA-ST-42: Porto de Santarém, que envolveu escavações arqueológicas em duas áreas: n. 2 e n. 2A (Figura 1).

As escavações no sítio foram realizadas com o intuito de averiguar anomalias geofísicas detectadas nas áreas por meio de estudo realizado com auxílio de GPR GSSI SIR-3000, com antena de frequência de $400 \mathrm{MHz}$ e janela de tempo de $70 \mathrm{~ms}$, além de investigar locais onde havia afloramento de bordas de vasilhas e fragmentos de cerâmica (Schaan 2012a). 


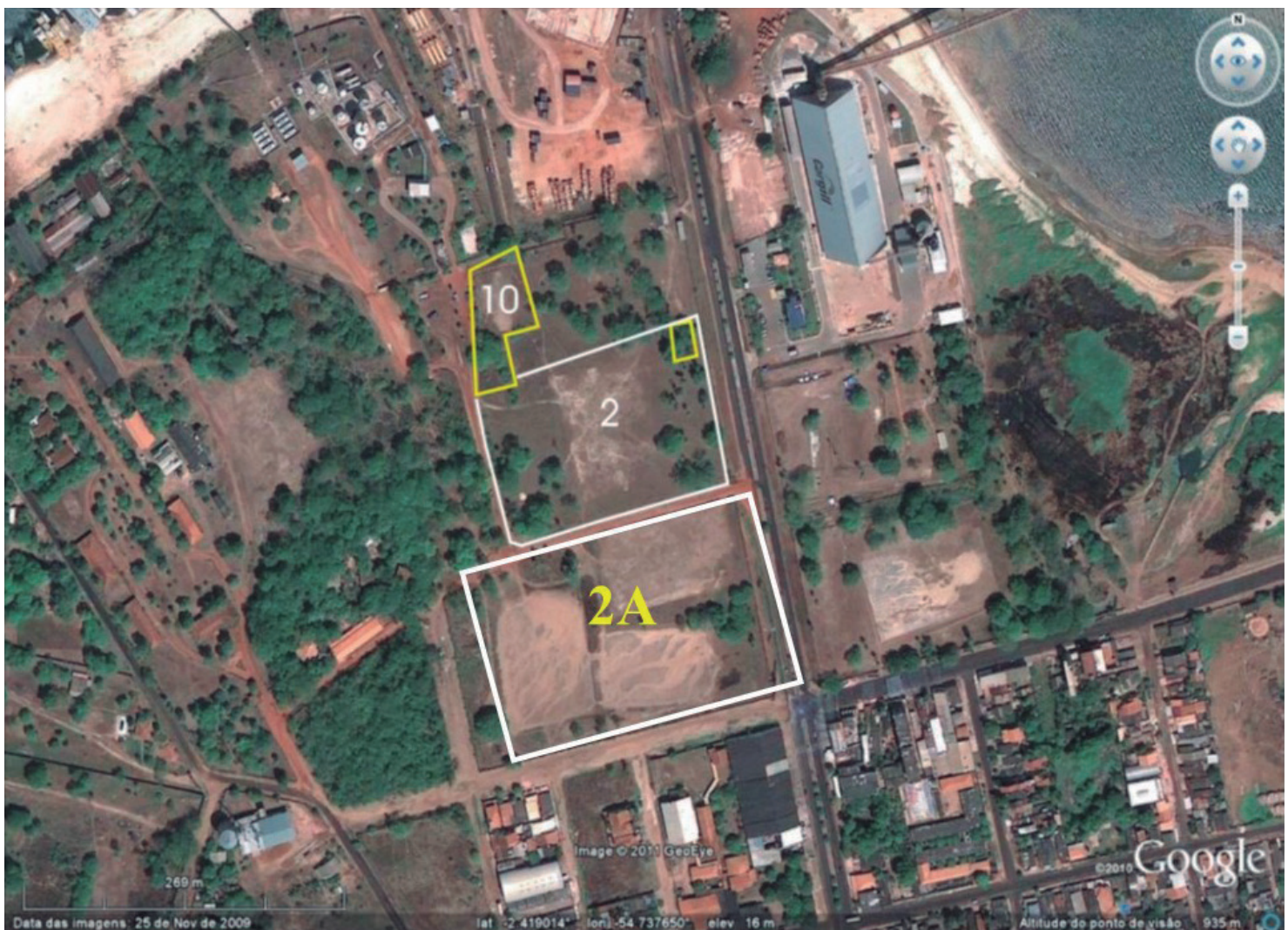

Figura 1 - Localização da área do porto de Santarém submetida a salvamento arqueológico, ressaltando as áreas 2 e 2a, nesta última foi encontrado o muiraquitã Santarém.

Fonte: Modificado de Schaan (2012a).

Dentre as várias anomalias escavadas, um tipo de estrutura recorrente foi os bolsões escavados no solo contendo camadas residuais de Terra Preta Arqueológica (TPA) bastante perturbadas, com presença de material descartado. Essas feições foram escavadas separadamente com o material coletado devidamente identificado, e registradas em fichas específicas, além de serem detalhadamente desenhadas e fotografadas (Schaan 2012a).

\section{Análises Morfológicas}

As análises foram realizadas no Laboratório de Mineralogia e Gemologia (PPGG/IG/UFPA), consistindo de medidas com auxílio de paquímetro, observações mesoscópicas em parte apoiadas por estereomicroscópio Zeiss, lápis de dureza (escala de Mohs), com medidas realizadas dentro do furo lateral e determinação da densidade com a balança de Kraus-Jholy. 


\section{Análises Mineralógicas}

Tendo em vista a manter a integridade do artefato arqueológico, as análises mineralógicas se detiveram ao uso da técnica de Difração de Raios $\mathrm{X}(\mathrm{DRX})$ diretamente sobre o artefato, favorecidas pelo tamanho pequeno do objeto, evitando-se assim a necessidade de obtenção de pó. Por esses motivos, as análises perderam um pouco de resolução. Empregou-se o difratômetro Bruker, modelo D2 Phaser, pertencente ao Laboratório de Mineralogia, Geoquímica e Aplicações (LAMIGA/PPGG/IG/ UFPA). Para a interpretação do respectivo espectro utilizou-se o programa X'pert High Score Plus, da PANalytical, do Laboratório de Caracterização Mineral (LMC/PPGG//UFPA). O equipamento foi equipado com anodo de cobre $(\lambda \mathrm{Cu} \mathrm{K} \alpha=1.54184$ $\AA$ ) e foi operado sob as seguintes condições: 30 $\mathrm{kV}$ voltagem e $10 \mathrm{~mA}$ corrente, 0.02 pitch e $0.2 \mathrm{~s}$ pitch time Lynxeye detector.

\section{Análises Químicas}

Da mesma forma que as análises mineralógicas, para manter a integridade do artefato, as análises químicas foram realizadas diretamente sobre o objeto, empregando-se fluorescência de Raios X portátil (FRX) com energia dispersiva e Microscopia Eletrônica de Varredura (MEV) também com Energia Dispersiva (EDX), o que em parte influenciou na menor resolução das análises. O equipamento de fluorescência de Raios X empregado foi o Bruker S 1 Turbo do Lamiga/ PPGG/UFPA. As análises por MEV, acopladas à espectrometria de Raios X (EDX), permitiram obter dados sobre a composição química geral e também imagens em escala micrométrica da superfície do artefato. Utilizou-se equipamento Hitachi modelo TM 3000 e o sistema EDX 3000 com software Swift $E D$. O artefato não foi metalizado, evitando assim qualquer dano a ele, sendo que as análises foram realizadas sob baixo vácuo.

\section{RESULTADOS E DISCUSSÕES}

\section{Escavação}

As feições escavadas apresentavam certa similaridade no conteúdo do material descartado, como fragmentos de cerâmica, peças líticas, remanescentes ósseos e carvão, por vezes concentrados em cavidades escavadas, o que indicou suas feições antrópicas, portanto, foram denominadas de feições culturais. Em algumas das feições foram exumados objetos muito singulares, como estatuetas inteiras ou fragmentos de partes de estatuetas femininas e masculinas, e o muiraquitã ST-42/602. 
Em uma das feições culturais (Feição 5), identificada na área $2 \mathrm{~A}$, situada imediatamente ao Sul da área 2 (Figuras 1 e 2), foi exumado o ST-42/602. Segundo Schaan (2012a), a área 2A se apresentava como terreno ligeiramente plano, sobre solo arenoso, úmido, compacto e duro. A coloração do solo variou de cinzento-escuro, cinzento muito escuro a bruno-escuro a amarelo avermelhado (7.5YR4/1, 7.5YR 3/1, 7.5YR 3/2, 7.5YR

6/6), indicando exposição dos latossolos, frequentes na região. Na área 2, ao Norte, predominou a coloração entre preta, cinzento muito escuro, bruno acinzentado-escuro e bruno (10YR2/1, 3/1, 4/2, 4/3 e 7.5YR4/2, 3/1), correspondente à TPA (Schaan 2012a), sugerindo que na área n. 2A, essa terra fora erodida pela ação antrópica recente.

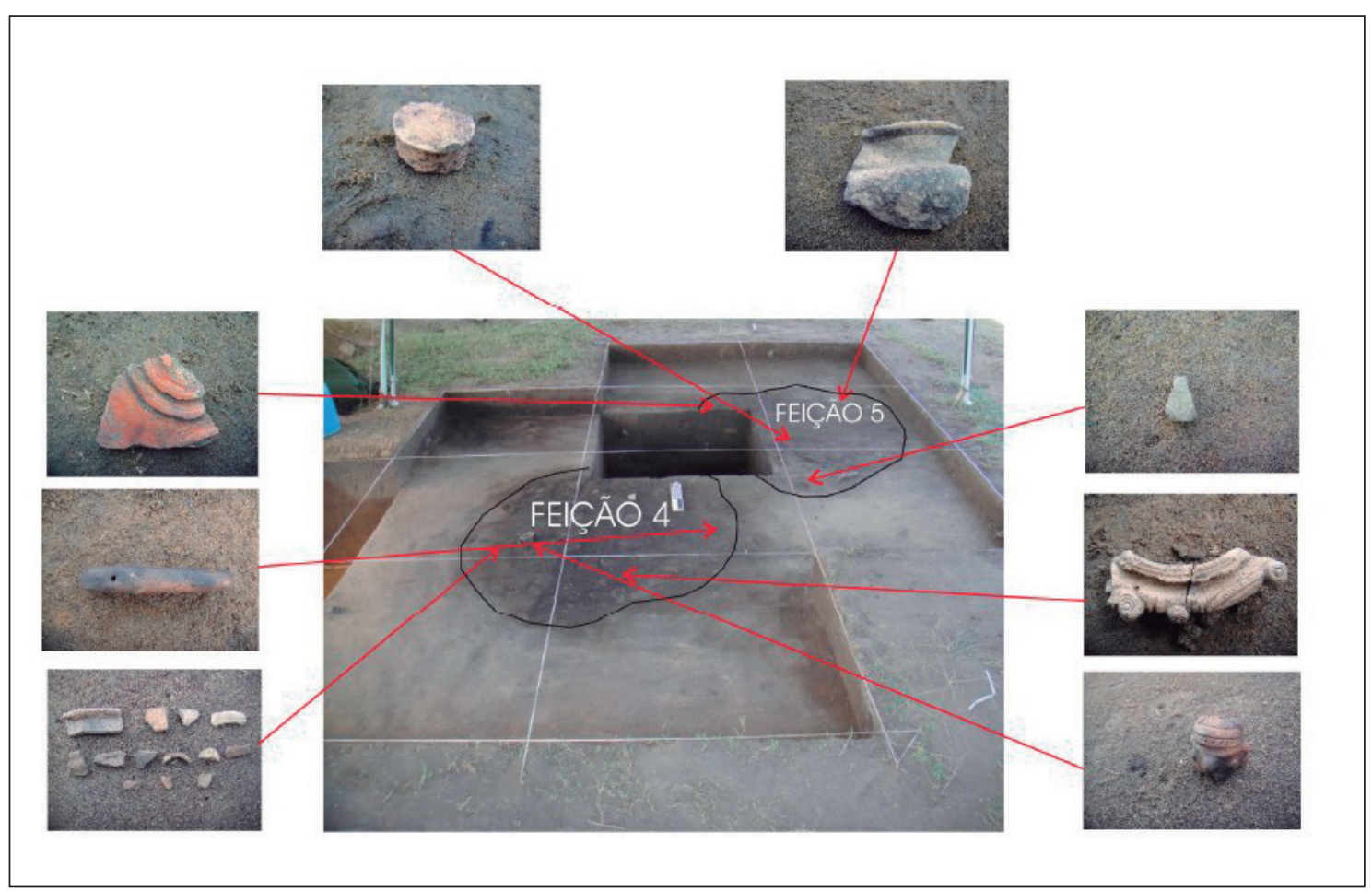

Figura 2 - Feições 4 e 5 aos $20 \mathrm{~cm}$ de profundidade (Schaan 2012a) na área 2a. A foto mostra a posição geral em que foi encontrado o muiraquitã Santarém, na feição 5, próximo ao limite com a feição 4 e também a riqueza em material cerâmico na feição 4 e em parte da feição 5 .

Fonte Schaan \& Alves (2015). 
Para a escavação da feição 5 (Figura 3) foram de coloração bruno amarelado-escuro (10YR abertas quatro unidades de $1 \mathrm{~m}^{2}$ (L32 U18, L32 4/4) e bruno amarelado (10YR 6/8) (Figura U19, L32 U20, I31 U20); segundo Schaan (2012a), 3). Praticamente todo o material exumado da o muiraquitã (Tombo ST-42/602, figura 4) foi escavação das quatro unidades estava concentrado encontrado no segundo nível de escavação (10-20 cm) da unidade L32 U18. A feição 5 apresentava forma oval e solo composto por TPA (10YR 2/1) no seu interior. A cavidade do bolsão escavada está intrusiva em um sedimento areno-argiloso, arqueologicamente estéril, seco e compactado dentro da feição 5, com maior ocorrência $(60,2 \%$, cerâmica e lítica) na unidade L32 U19, fato que, segundo Schaan (2012a), corroborava a ideia de que a área foi utilizada para descarte proposital dentro dessa estrutura e em um dado momento de ocupação deste sítio.

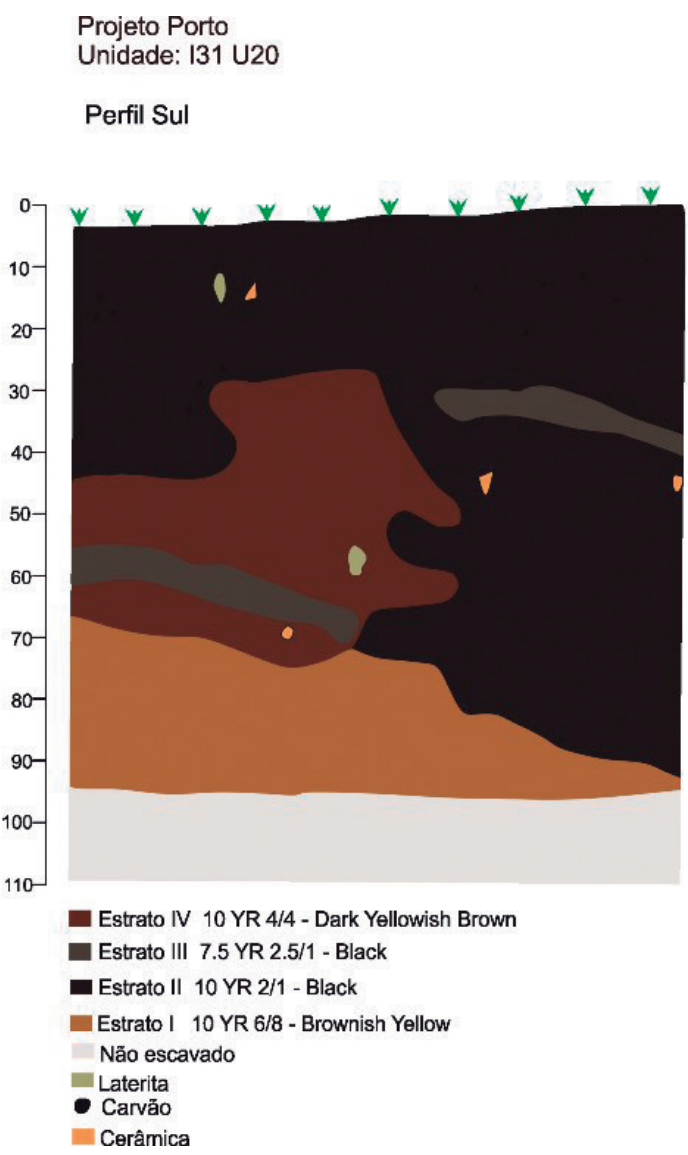

Projeto Porto
Unidade: 131 U2

Perfil Oeste

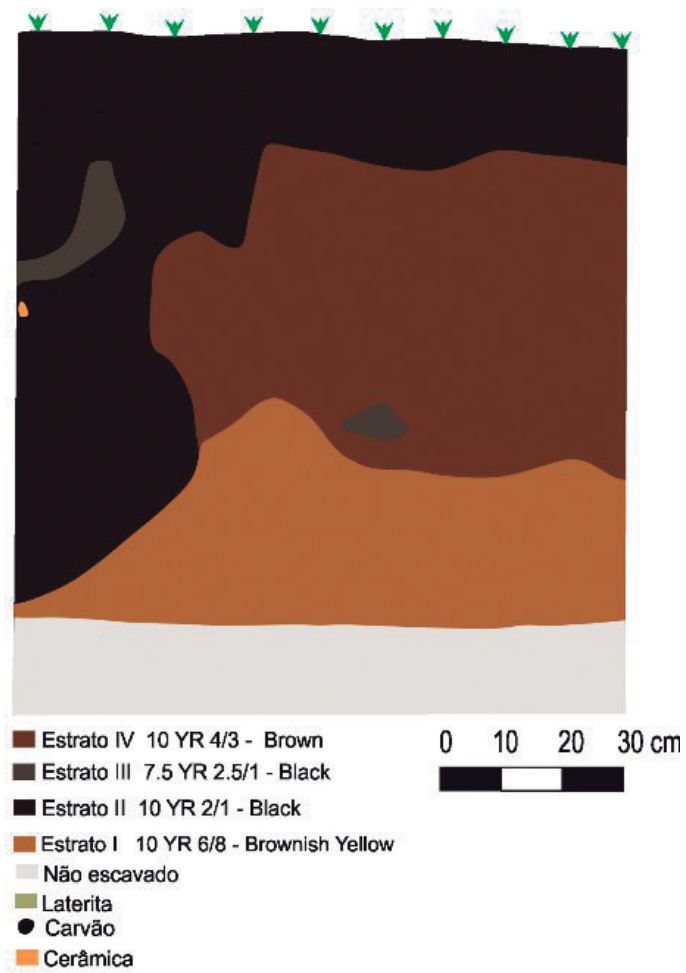

Figura 3 - Perfil Sul e Oeste da Unidade I31 U20 (Schaan2012a). 


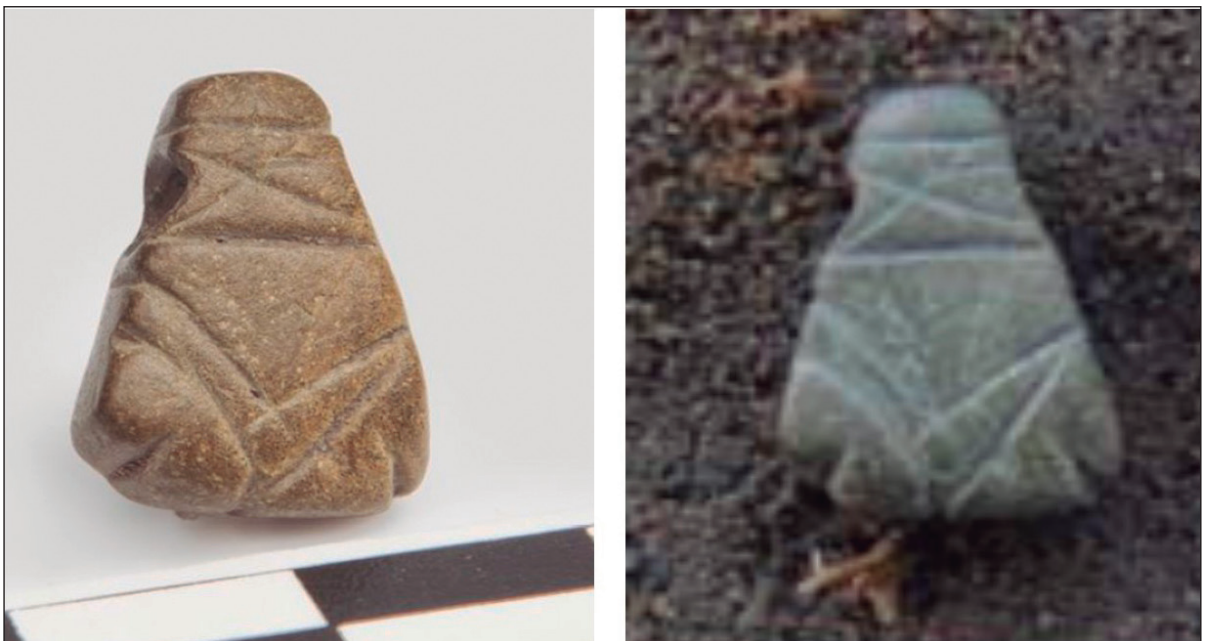

Figura 4 - Imagens do muiraquitã Santarém (ST-42/602) capturadas do relatório de Schaan (2012a) ao tempo da coleta. Notar as diferenças na tonalidade: à direita, infelizmente com pouco foco e contraste, representa a cor mais próxima à da real.

A escavação desta estrutura atingiu $90 \mathrm{~cm}$ de profundidade. A partir do nível 30-40cm há uma redução significativa do material arqueológico, mais de $50 \%$ do material ocorre entre os níveis $0-10 \mathrm{~cm}$ e 20-30cm (Figura 5). O conjunto do material cerâmico exumado inclui fragmentos com decoração variada: engobo vermelho, filete aplicado, inciso, modelado, ponteado, digitado, acanalado, entalhado, aplique, braço de estatueta, base de estatueta, pintura vermelha, pintura policroma e um modelado zoomorfo bicéfalo. No conjunto de peças líticas, a maioria associada a uma indústria de lascamento (e.g. núcleos, lascas, e detritos de lascamento), há o muiraquitã, um pingente de forma fálica, abrasadores sulcados, um alargador em arenito e uma lâmina de machado polido, também foram exumados alguns fragmentos de ossos queimados de animais (Schaan 2012a).
Schaan e Alves (2015: p.47) sugerem, baseadas na presença do muiraquitã e outros artefatos como estatuetas, que as estruturas associadas às feições "não eram tratadas com uma área de descarte coletivo ou de qualquer objeto, mas sim que possuíam significados particulares".

Três amostras de carvão coletadas nos níveis $53 \mathrm{~cm}, 69 \mathrm{~cm}$ e $87 \mathrm{~cm}$ das unidades escavadas e dentro da feição 5 sugerem que esta estrutura representa um evento único temporalmente, escavada e utilizada por volta de 540 anos antes do presente (AP) (Schaan 2012a). Todas as três amostras datadas resultaram em valores estatisticamente iguais (Tabela 1). Cronologicamente, a feição 5 está associada ao apogeu da fase Santarém, congruente com o material arqueológico exumado de seu interior (Schaan 2012 a 2012b). 


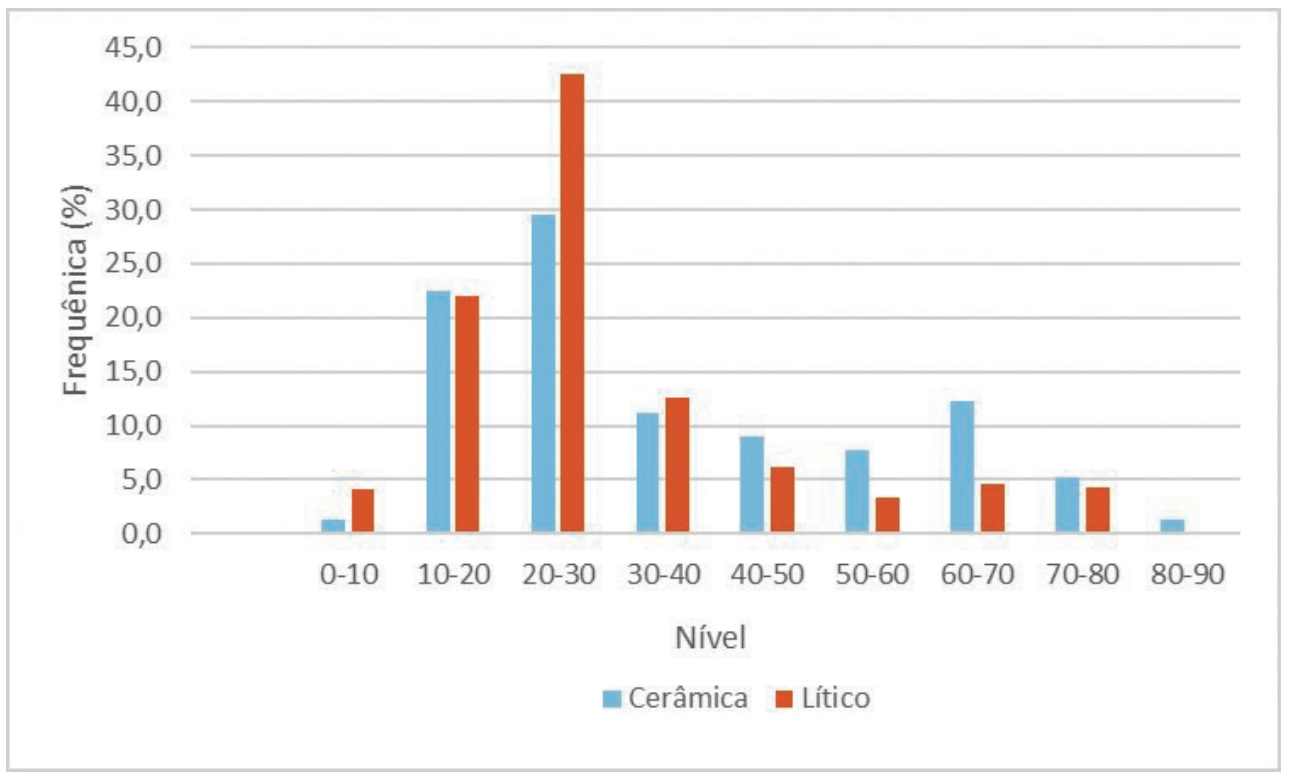

Figura 5 - Frequência do material cerâmico e lítico exumado da feição 5 por níveis de escavação. Elaboração: conforme dados de Schaan (2012a).

\begin{tabular}{|c|c|c|c|c|c|c|c|}
\hline \multirow[b]{2}{*}{ AMOSTRA } & \multirow[b]{2}{*}{ UNIDADE } & \multirow[b]{2}{*}{$\begin{array}{l}\text { NİVEL } \\
(\mathrm{cm})\end{array}$} & \multirow[b]{2}{*}{$\begin{array}{l}\text { CONVENCIONAL } \\
\text { (AP) }\end{array}$} & \multicolumn{2}{|l|}{ DATA } & \multirow[b]{2}{*}{$\delta^{13} \mathrm{C}$} & \multirow[b]{2}{*}{$\begin{array}{c}\mathrm{N}: \text { BETA } \\
\text { ANALYTIC }\end{array}$} \\
\hline & & & & $\begin{array}{l}\text { CALIBRADA } \\
\text { (calAD) }\end{array}$ & $\begin{array}{l}\text { CALIBRADA } \\
\text { (calAP) }\end{array}$ & & \\
\hline P S T M - 018 & L32 U18 & 53 & $540 \pm 30$ & $\begin{array}{c}1320 \text { a } 1350 \text { e } \\
1390 \text { a } 1430\end{array}$ & $\begin{array}{c}630 \text { a } 600 \text { e } 560 \\
\text { a } 520\end{array}$ & -25.7 & 322210 \\
\hline P S T M - 016 & I31 U20 & 68 & $530 \pm 30$ & $\begin{array}{c}1320 \text { a } 1340 \text { e } \\
1390 \text { a } 1440\end{array}$ & $\begin{array}{c}630 \text { a } 610 \text { e } 560 \\
\text { a } 510\end{array}$ & -26.5 & 322227 \\
\hline P S T M - 015 & L32 U20 & 87 & $550 \pm 30$ & $\begin{array}{c}1320 \text { a } 1350 \text { e } \\
1390 \text { a } 1430\end{array}$ & $\begin{array}{c}630 \text { a } 600 \text { e } 560 \\
\text { a } 520\end{array}$ & -26.0 & 322226 \\
\hline
\end{tabular}

Tabela 1 - Datações absolutas (2s) por radiocarbono. Fonte: Schaan 2012a, 2012b.

Feições do tipo bolsão foram encontradas em Santarém e em outros sítios do baixo Amazonas (Guapindaia 2008, Gomes 2008, 2010, Roosevelt de lâmina de machado e um alargador, próximo 2009, Duarte-Talim 2012, Gomes \& Luiz 2013, ao muiraquitã ST-42/602 (Araújo da Silva 2016, Araújo da Silva 2016, Silva 2016, Troufflard 2017, Schaan 2012a). Para o material cerâmico, foi Troufflard \& Alves 2019). Entre o material lítico, os possível verificar fragmentos de vasos globulares tipos de artefatos encontrados foram lascas, dentes de roedores, polidores, calibradores, fragmentos ao muiraquitã ST-42/602 (Araújo da Silva 2016, 
e de pratos, em geral com grande diversidade de decorações cromáticas e plásticas (Silva 2016, Schaan 2012a).

\section{Morfologia do Pingente}

O muiraquitã Santarém (Figuras 4 e 6) apresenta coloração cinza-esverdeada, é compacto e maciço, apresentando dureza baixa ( $\leq 3$ na escala de Mohs) e com ligeiro aspecto untuoso. Exibe formato trapezoide, com $18 \mathrm{~mm}$ de altura (comprimento), largura maior de 12,5 mm (base dos pés) e menor de $5 \mathrm{~mm}$ (base menor à cabeça) e espessura máxima de $6 \mathrm{~mm}$. Pesa $1,96 \mathrm{~g}$ e sua densidade medida é de $2,84 \mathrm{~g} / \mathrm{cm}^{3}$. Em termos gerais, as incisões, que são sulcos retos e ligeiramente curvilíneos, com bordas boleadas e fundo côncavo, ressaltam os contornos de forma batraquiana, esculpida apenas na face frontal, enquanto a posterior é lisa e boleada nas arestas de contorno. São notáveis os pontos de picotagem em todo o corpo da peça na face frontal. O furo lateral é bem evidente, bicônico e à altura do possível pescoço. Na parte posterior é possível visualizar as estrias de abrasão e também perdas irregulares de material. Pela descrição e as imagens pode-se deduzir que a peça não atingiu alto nível de elaboração, se confrontada com vários muiraquitãs em nefrita do acervo do MAE e do Museu do Encontro (Costa et al. 2002, Meirelles et al. 2012), da Boca do Rio na Baixada Maranhense (Navarro et al. 2017) ou ainda de Pearls, no Mar de Caribe (Falci et al. 2020), pois lhe falta o destaque dos olhos, do pescoço, além de polimento e brilho. Provavelmente, a natureza da matéria-prima não tenha permitido dar polimento e brilho.
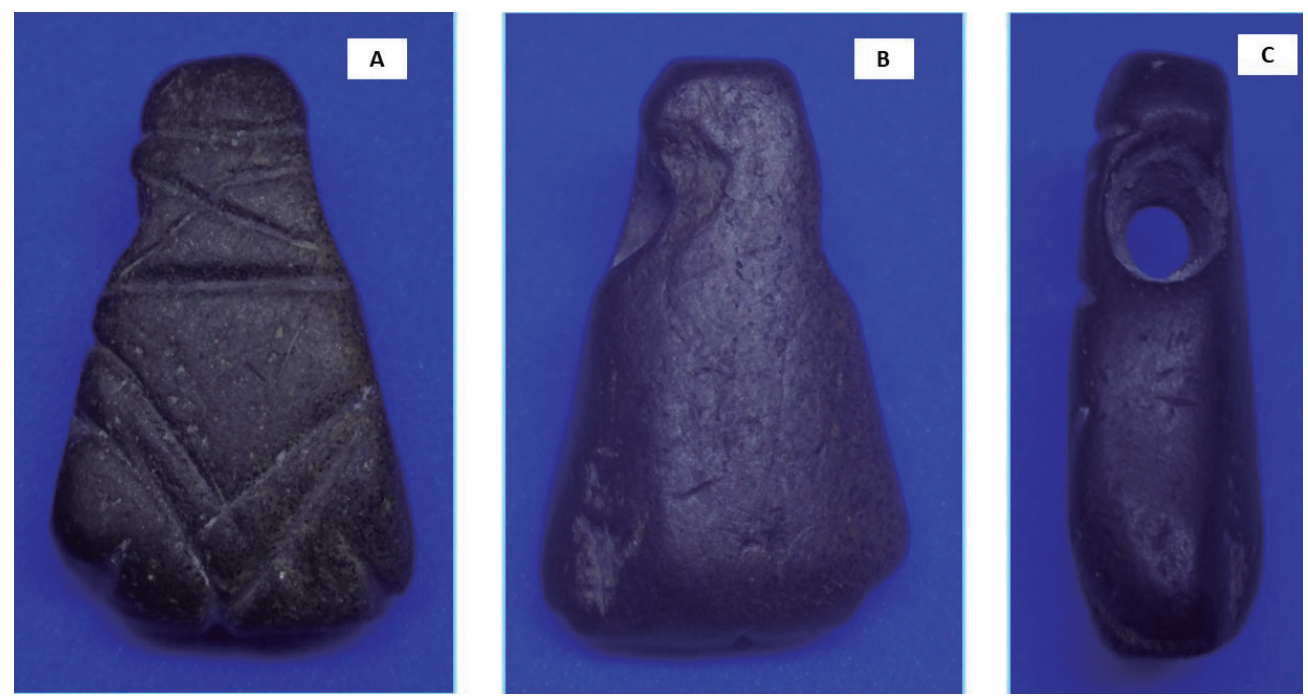

Figura 6 - Imagens mesoscópicas do pingente Santarém: 6a) Frontal 6b) Posterior 6c) Lateral mostrando o furo bicônico. 


\section{Características mineralógicas e petrográficas}

As análises por DRX demonstraram que o material empregado para esculpir o muiraquitã Santarém (ST-42/602) é multiminerálico, compreendendo clinocloro (clorita), quartzo, sericita (muscovita fina) e albita, em ordem decrescente de abundância; e possivelmente ainda apatita e calcita como acessório (Figuras 7 e 8b). Essa constituição mineralógica aliada à granulação fina do material como um todo, o que, segundo a fotomicrografia eletrônica de varredura (Figura 8a), é foliado, sugere que ele corresponda a uma rocha metamórfica tipo clorita-sericitaquartzo xisto e, menos provável, a uma formação mineral hidrotermal de média temperatura, como alteração de rocha ígnea máfica. Essa constituição mineralógica e a possível rocha são expressões frequentes em terrenos geológicos Proterozoicos da Amazônia e também recorrente em muitas outras regiões da superfície da Terra. Por essas características, o muiraquitã Santarém não foi elaborado em material raro, como jade, nem mesmo jade nefrítico, já que não apresentou o seu mineral característico, tremolita e/ou tremolitaactinolita, observado em vários muiraquitãs tidos como procedentes da Amazônia, incluindo aquele contextualizado do sítio Boca do Rio (Navarro et al. 2017) ou seus equivalentes em formato da região do Caribe (Boomert 1987, Queffelec et al. 2018, Falci et al. 2020).

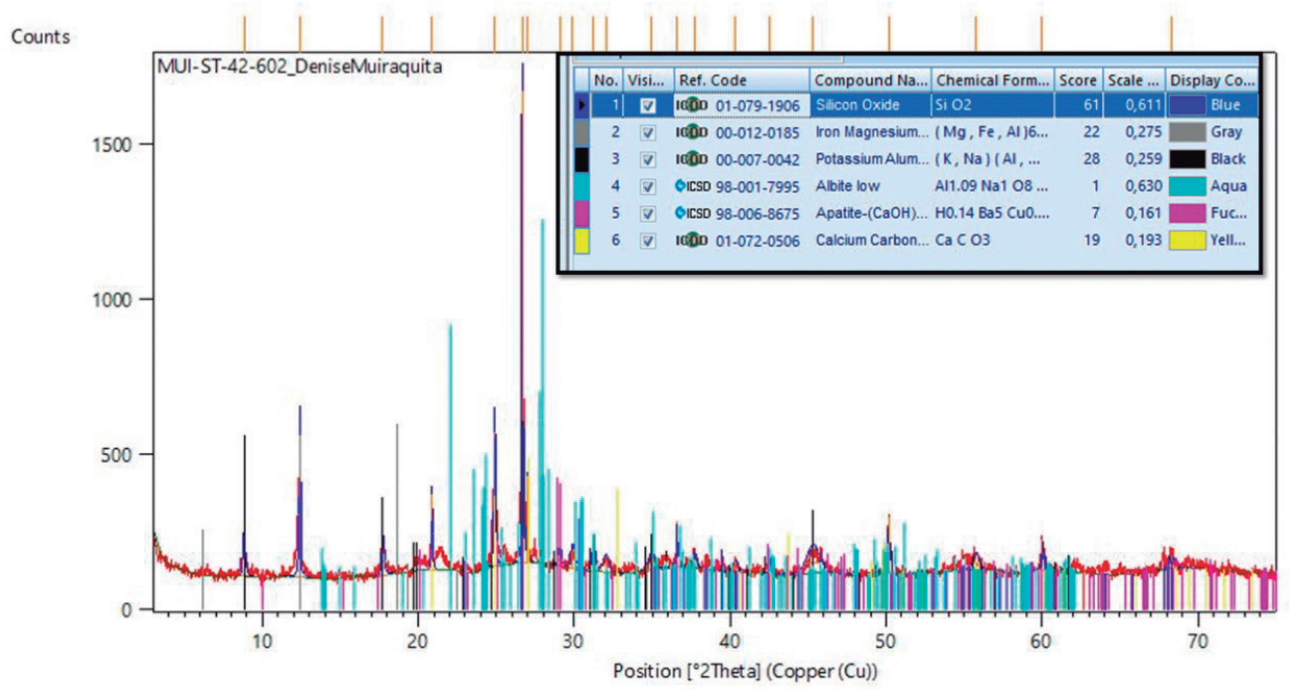

Figura 7 - Difratograma de Raios X obtido sobre a superfície do pingente Santarém em sua face frontal, mostrando o domínio de clinocloro (Iron Magnesium), quartzo (Silicon Oxide), sericita (Potassium Alum) e albita (Albite), além de calcita (Calcium Carbon) e apatita (Apatite-), como acessórios. 


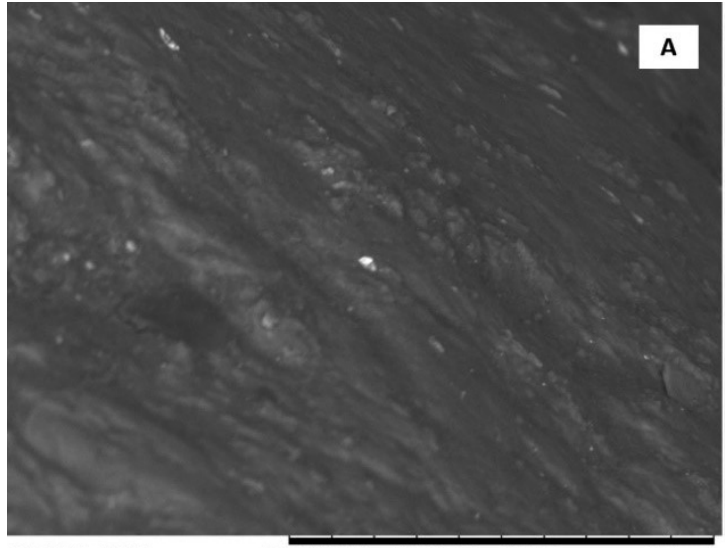

TM3000_1227
$2019 / 08 / 3016: 28$ AL $\overline{D 11.2}$

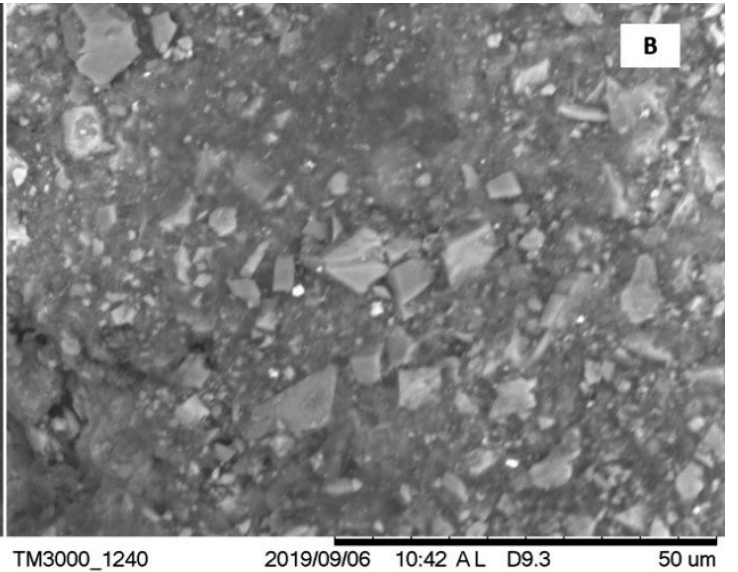

Figura 8 - Fotomicrografias de MEV sobre microáreas na superfície frontal do muiraquitã Santarém: 8a) É possível reconhecer a foliação metamórfica e granulação fina dos constituintes minerais;

8b) Microbolsões dominados por romboedros de calcita.

\section{Composição Química e Microquímica}

A composição química total obtida por FRX sobre a superfície geral do pingente (Tabelas 2 e 3 ) mostra um amplo espectro de elementos químicos, típico de composição multimineral, rica em minerais de alumínio, cujo teor está um pouco acima de $31 \%$ de $\mathrm{Al}_{2} \mathrm{O}_{3}$, que, ao lado dos teores medianos de $\mathrm{SiO}_{2}$ (da ordem de 53\%), ressaltam o domínio de aluminossilicatos, demonstrados pela abundância de sericita (confirmada pelos teores de $\mathrm{K}_{2} \mathrm{O}$ ) e albita $\left(\mathrm{Na}_{2} \mathrm{O}+\mathrm{CaO}\right)$. Essa composição normalmente é encontrada em rochas metamórficas derivadas de sedimentares argilosas, ou então de rochas máficas hidrotermalizadas. Os teores de $\mathrm{SiO}_{2}$ são condizentes com essas composições rochosas, compatível comando à menor presença de quartzo.
Por sua vez, o teor elevado de ferro $\left(\mathrm{Fe}_{2} \mathrm{O}_{3}\right.$ em torno de $11 \%$ ) expressa a presença elevada de clorita ferrosa a magnésio-ferrosa (clinocloro), que confere a cor escura à rocha como um todo. Os teores de $\mathrm{P}_{2} \mathrm{O}_{5}$, por volta de $0.36 \%$ correspondem, estequiometricamente, a pouco mais de $1 \%$ de apatita e reforçam a identificação desse mineral acessório por DRX. Parte dos teores de cálcio deve corresponder à presença de calcita, identificada por DRX. Esse método, por outro lado, não permitiu identificar o mineral representativo ao $1.5 \%$ de $\mathrm{TiO}_{2}$, confirmado pelas análises MEV/EDX, que está na ordem de grandeza de rochas máficas.

Os resultados de análises químicas obtidos por MEV/EDX (Tabela 3) para três áreas micrométricas na superfície do pingente mostram a amplitude química do seu material, como visto anteriormente, 
incluindo a presença de sódio e magnésio em localmente elevados (até 5,313\% de cálcio na tabela valores que justificam a presença de albita (teor 3) retratam a presença de microbolsões de calcita de $\mathrm{Na}$ e em parte de $\mathrm{Ca})$ e da clorita magnésio- $\left(\mathrm{CaCO}_{3}\right)$, confirmada pelos cristais romboédricos ferrosa tipo clinocloro, respectivamente. Os teores da fotomicrografia eletrônica (Figura 8b).

\begin{tabular}{|l|r|r|}
\hline Componentes químicos & FRX (1) & FRX (2) \\
\hline $\mathrm{SiO}_{2}$ & 54,60 & 52,80 \\
\hline $\mathrm{TiO}_{2}$ & 1,56 & 1,54 \\
\hline $\mathrm{Al}_{2} \mathrm{O}_{3}$ & 31,90 & 31,10 \\
\hline $\mathrm{MgO}$ & $\mathrm{na}$ & $\mathrm{na}$ \\
\hline $\mathrm{Fe}_{2} \mathrm{O}_{3}$ & 11,00 & 10,60 \\
\hline $\mathrm{CaO}$ & 0,91 & 1,04 \\
\hline $\mathrm{K}_{2} \mathrm{O}$ & 3,14 & 3,03 \\
\hline $\mathrm{Na}_{2} \mathrm{O}$ & $\mathrm{na}$ & $\mathrm{na}$ \\
\hline $\mathrm{MnO}_{2}$ & 0,033 & 0,032 \\
\hline $\mathrm{P}_{2} \mathrm{O}_{5}$ & 0,36 & 0,36 \\
\hline $\mathrm{S}$ & 0,031 & 0,05 \\
\hline $\mathrm{Cl}$ & 0,082 & 0,097 \\
\hline $\mathrm{Cr}$ & 0,033 & 0,030 \\
\hline $\mathrm{V}$ & 0,028 & 0,018 \\
\hline $\mathrm{Total}$ & 103,68 & 100,67 \\
\hline
\end{tabular}

Tabela 2 - Composição química do muiraquitã Santarém obtida sobre a superfície de sua face posterior por FRX portátil, técnica que não permitiu analisar $(\mathrm{Na}) \mathrm{MgO}$ e $\mathrm{Na}_{2} \mathrm{O}$.

\begin{tabular}{|l|r|r|r|}
\hline Análises & $\mathbf{1}$ & 2 & 3 \\
\hline Elementos & Peso em \% & Peso em \% & Peso em \% \\
\hline Oxigênio (O) & 58,621 & 58,291 & 46,864 \\
\hline Sódio $(\mathrm{Na})$ & 0,861 & 0,995 & 1,283 \\
\hline Magnésio $(\mathrm{Mg})$ & 1,589 & $\mathrm{Nd}$ & 0,894 \\
\hline Alumínio $(\mathrm{Al})$ & 12,121 & 15,706 & 15,781 \\
\hline Silício $(\mathrm{Si})$ & 15,858 & 19,050 & 21,929 \\
\hline Enxofre (S) & $\mathrm{Nd}$ & $\mathrm{Nd}$ & 1,331 \\
\hline Cloro $(\mathrm{Cl})$ & 1,008 & 0,623 & 2,353 \\
\hline Potássio (K) & 1,179 & 1,370 & 1,999 \\
\hline Cálcio $(\mathrm{Ca})$ & 5,313 & 0,956 & 3,549 \\
\hline Titânio $(\mathrm{Ti})$ & 0,389 & $\mathrm{Nd}$ & 0,622 \\
\hline Ferro $(\mathrm{Fe})$ & 3,060 & 3,009 & 3,394 \\
\hline
\end{tabular}

Tabela 3 - Composição microquímica (análise pontual micrométrica) do pingente Santarém obtida sobre a superfície de sua face posterior por MEV/EDX, que ao contrário da técnica FRX portátil mencionada na tabela 1, permitiu determinar os teores de sódio e magnésio (Nd: não detectado). 


\section{CONCLUSÕES}

O muiraquitã Santarém é talvez o primeiro encontrado em contexto arqueológico na região do baixo Amazonas, das lendárias Amazonas de Carvajal, o centro das lendas e dos relatos orais e escritos sobre os muiraquitãs. Infelizmente, o exemplar, embora esculpido em rocha verdeescura, não tem a composição de jade, nem mesmo o nefrítico. A matéria-prima empregada equivale à clorita-sericita-quartzo xisto, de cor cinzaesverdeada, textura muito fina e microfoliada, dureza baixa, e por esses motivos, não se pode classificá-la como matéria-prima rara, o que não desmerece sua raridade e sua importância arqueológica, além de ser um mérito singular para o fortalecimento da verdade sobre as lendas dos muiraquitãs, já que seu legado parece querer fortalecer um elo sociocultural e econômico entre o baixo Amazonas e a região amazônica costeira atlântica internacional até o Caribe. Apesar da raridade dos muiraquitãs, a caracterização químico-mineralógica realizada em coleções arqueologicamente descontextualizadas, e agora em peças exumadas in situ por meio de escavações controladas, tem demonstrado que a matéria-prima empregada na confecção dos adornos tem sido, em sua maioria, o jade nefrítico, confeccionados a partir da tremolita e actinolita, materiais que podem ser encontradas no baixo Amazonas, desmitificando a ideia de matéria-prima exótica; e consequentemente, as hipóteses de redes de circulação dos muiraquitãs e/ou de matéria-prima de grandes distâncias, por vezes, transoceânicas. Por outro lado, a identificação de que o muiraquitã ST-42/602 fora confeccionado em clorita-sericitaquartzo xisto pode sugerir que algumas peças, as quais se diferenciariam pelo tipo de matéria-prima, teriam sido talvez para uso próprio da cultura tapajônica, enquanto outras eram utilizadas nas redes de trocas entre as elites amazônicas.

\section{AGRADECIMENTOS}

Eles se estendem ao apoio financeiro do CNPQ (Grant 305015/2016-8), ao PPGA /UFPA, aos Lamiga/PPGG/UFPA e ao convite feito por Renata Godoy para participar do dossiê em homenagem à Dra. Denise Schaan. A presente pesquisa se enriqueceu com a contribuição do relatório de Schaan, e é nossa singular homenagem a essa pesquisadora, que tão prematuramente nos deixou, mas nos enriqueceu com um portentoso legado. 


\section{REFERÊNCIAS}

Araújo da Silva, T.S. 2016. Banquete lapidoso: tecnologia lítica em contextos festivos no sítio Porto de Santarém, Baixo Amazonas. Dissertação de mestrado, Programa de Pós-Graduação em Antropologia, Universidade Federal de Minas Gerais, Brasil.

Barata, F. 1954. O muiraquitã e as contas dos Tapajós. Revista do Museu Paulista8: 229-259.

Barreto, C. 2017. Figurine Traditions from the Amazon in The Oxford Handbook of Prehistoric Figurines. Editado por T. Insoll, pp.417-442. Oxford: Oxford University Press.

Boomert, A. 1987. Gifts of the amazons: green stone pendants and beads as items of ceremonial exchange in Amazonia and Caribbean. Antropologica 67: 33-54.

Costa, M.L., A.C.R.L. Silva, e R.S. Angélica. 2002a. Muyrakytã ou muiraquitã, um talismã arqueológico em jade procedente da Amazônia: uma revisão histórica e considerações antropogeológicas. Acta Amazonica 32(3): 467-490.

Costa, M.L. et al. 2002b. Muiraquitã ou muyrakytã, um talismã arqueológico em jade procedente da Amazônia: aspectos físicos, mineralogia, composição química e sua importância etnogeográficageológica. Acta Amazonica 32 (3): 431-448.

Duarte-Talim, D. L. 2012. As indústrias líticas das ocupações ceramistas da Amazônia: Estudo do sítio PA-OR-127: Cipoal do Araticum, região de Porto Trombetas, estado do Pará. Dissertação de Mestrado, Programa de Pós-Graduação em Antropologia, Universidade Federal de Minas Gerais, Brasil.

Falci, G.C. et al. 2020. Lapidary production in the eastern Caribbean: a typo-technological and microwear study of ornaments from the site of Pearls, Grenada. Archaeological and Anthropological Sciences 12:53.

Fonseca, J.A. 2010. As estatuetas líticas do baixo Amazonas, in Arqueologia amazônica. Organizado por E. Pereira, e V. Guapindaia, pp. 237-257. Belém: MPEG/IPHAN/SECULT. v. 1.

Gomes, D.M.C. 2008. Cotidiano e poder na Amazônia Pré-Colonial. São Paulo: Edusp, 240p. 
Gomes, D.M.C. 2010. Os contextos e os significados da arte cerâmica dos Tapajó, in Arqueologia amazônica. Organizado por E. Pereira, e V. Guapindaia, pp. 213-234. Belém: MPEG/IPHAN/SECULT.

Gomes, D., J. G. Luiz 2013. Contextos domésticos do sítio do Porto, Santarém, Pará, identificados a partir de contribuição da geofísica por meio do método GPR. Boletim do Museu Paraense Emílio Goeldi, Ciências Humanas 8:3: 639-656.

Guapindaia, V. L. C. 2008. Além da margem do rio - a ocupação Konduri e Pocó na região do Porto Trombetas, PA. Tese de doutorado, Museu de Arqueologia e Etnologia, Programa de Pós-Graduação em Arqueologia Universidade de São Paulo, Brasil.

Lima, A.M.A. 2018. A Ecologia de Assentamentos, Interações Sociais Ameríndias e o Contexto Geográfico dos Muiraquitãs no Baixo Amazonas. Cadernos do Lepaarq 15 (30): 121-141.

Lopes, R. 1924. A civilização lacustre do Brasil. Boletim do Museu Nacional 1 (2): 87-109.

Meirelles, A.C.R., e M.L. Costa, 2012. Mineralogy and chemistry of green stone artifact (muiraquitãs) from the museums of the Brazilian State of Pará. REM: Revista da Escola de Minas 65(1): 59-64.

Moraes, C.P., A.M.A. Lima, e R.A. Santos. 2013. Os artesãos das Amazonas: a diversidade da indústria lítica dos Tapajó e o muiraquitãin Antes de Orellana: Actas del 3er Encuentro Internacional de Arqueología Amazónica. Editado por S. Rostain, pp. 133-140. Lima: Instituto Francés de Estudios Andinos.

Navarro, A.G. 2013. O povo das águas: carta arqueológica das estearias da porção Centro-Norte da Baixada Maranhense. Caderno de Pesquisas 20 (3): 57-64.

Navarro, A.G. et al. 2017. O muiraquitã da estearia da Boca do Rio, Santa Helena, Maranhão: estudo arqueológico, mineralógico e simbólico. Bol. Mus. Paraense Emilio Goeldi, Cienc. Hum. 12(3): 869-894.

Navarro, A.G., A, Prous. 2020. Os muiraquitãs das estearias do Lago Cajari depositados no Museu Naciona (RJ): estudo tecnológico, simbólico e de circulação de bens de prestígio. Revista de Arqueologia 33(2): 66-91.

Neves, E.G. Arqueologia da Amazônia. 2006. Rio de Janeiro: Editora Zahar. 
Queffelec, A. et al. 2018. Local production and long-distance procurement of beads and pendants with high mineralogical diversity in an early Saladoid settlement of Guadeloupe (French West Indies). fournal of Archaeological Science: Reports 21:275-288.

Rodrigues, B., 1899. O muyrakytã e os ídolos simbólicos. 2. ed. Rio de Janeiro: Imprensa Nacional. v. 1. Roosevelt, A. 2009 A historical memoir of archaeological research in Brazil (1981-2007). Boletim do Museu Paraense Emílio Goeldi - Ciências Humanas 4 (1): 155-170.

Rostain, S. 2013. Island in the Rainforest: Landscape Management in Pre-Columbian Amazonia. Walnut Creek: Left Coast Press.

Schaan, D.P. 2012a. Salvamento arqueológico do sítio PA-ST-42: porto de Santarém - ano 2. UFPA/CDP. Relatório Final. v. 1.

Schaan, D.P. 2012b. Salvamento arqueológico do sítio PA-ST-42: porto de Santarém - ano 2. UFPA/CDP. Relatório Final. v. 2.

Schaan, D.P., e D.T. Alves. 2015. Um porto, muitas histórias: Arqueologia em Santarém. Belém: Gráfica Supercores.

Silva, A.C.R.L., M.L. Costa,, R.S.Angélica. 1998. O muiraquitã (muyrakytã): REM: Revista da Escola de Minas 51(2): 24-29.

Silva, A. B.C. 2016. Do luxo ao lixo: um estudo do material cerâmico dos bolsões do sítio Porto de Santarém, Baixo Amazonas. Dissertação de Mestrado, Programa de Pós-Graduação em Antropologia, Universidade Federal do Pará, Brasil.

Troufflard, J. 2017. Relationship between upland and riverine settlements in the Lower Amazon region during late precolonial times. Tese de Doutorado, Universidade da Flórida, EUA.

Troufflard, J., D.T. Alves. 2019. Uma abordagem interdisciplinar do sítio arqueológico Cedro, baixo Amazonas. Boletim Museu Paraense Emílio Goeldi, Ciências Humanas 14(2): 553-580. 